\section{Ventilation Strategies for Acute Lung Injury and Acute Respiratory Distress Syndrome}

To the Editor: Limiting plateau pressures in the respiratory system of patients with acute lung injury and acute respiratory distress syndrome (ALI/ARDS) to 28 to $30 \mathrm{~cm} \mathrm{H}_{2} \mathrm{O}$ may help guarantee lung protection. ${ }^{1}$ In the large multicenter Express trial, Dr Mercat and colleagues ${ }^{2}$ set positive end-expiratory pressure (PEEP) as high as possible to avoid plateau pressure above 28 to $30 \mathrm{~cm} \mathrm{H}_{2} \mathrm{O}$ (mean, $27.5 \mathrm{~cm}$ $\mathrm{H}_{2} \mathrm{O}$ ). In the lower PEEP (minimal distention) group in the Express trial, plateau pressure was kept as low as possible to maintain oxygenation targets (mean, $21 \mathrm{~cm} \mathrm{H}_{2} \mathrm{O}$ ). There was no difference in mortality between the 2 groups, but the higher PEEP/plateau pressure (increased recruitment) group showed a greater number of ventilator-free and organ failure-free days. Plateau pressure in the increased recruitment group dropped to $24 \mathrm{~cm} \mathrm{H}_{2} \mathrm{O}$ within the first week.

Two smaller trials $\left(n=53^{3}\right.$ and $\left.n=103^{4}\right)$ showed that higher PEEP levels, comparable with the Express trial (14-16 cm $\mathrm{H}_{2} \mathrm{O}$ ), can reduce mortality in ARDS, despite using plateau pressures that have been considered unsafe. Both studies started out with a plateau pressure of 32 and $31 \mathrm{~cm} \mathrm{H}_{2} \mathrm{O}$, respectively, but within 1 week they only needed a plateau pressure of 24 to $26 \mathrm{~cm} \mathrm{H}_{2} \mathrm{O}$.

There are 2 main differences between these studies and the Express trial. In the smaller trials, plateau pressure before lung protective ventilation was 30 to $32 \mathrm{~cm} \mathrm{H}_{2} \mathrm{O}$ compared with $23 \mathrm{~cm} \mathrm{H}_{2} \mathrm{O}$ in the Express study, at comparable PEEP levels $\left(8 \mathrm{~cm} \mathrm{H}_{2} \mathrm{O}\right)$ and tidal volumes. Also, both smaller studies used standardized ventilator settings with the patients to see whether ARDS criteria (ratio of partial pressure of arterial oxygen over fraction of inspired oxygen $\left[\mathrm{PaO}_{2}: \mathrm{FIO}_{2}\right]<200 \mathrm{~mm} \mathrm{Hg}$ ) were maintained over a set time period.

Alterations in chest wall mechanics may also result in marked differences in the real transpulmonary pressure, leading to progressive lung derecruitment and ventilatorinduced lung injury (VILI). ${ }^{5}$ Recruitment maneuvers may improve lung function by allowing ventilation on the deflation limb of the pressure-volume curve, resulting in higher end-expiratory lung volumes at similar airway pressures and potentially minimizing VILI. ${ }^{5}$

Arbitrarily limiting plateau pressure without individualized settings, with potential resultant progressive lung derecruitment, may prevent advances in lung protective ventilation. An individually titrated recruitment maneuver leading to an early short-term increase in plateau pressure, especially in more severely hypoxemic patients with altered chest wall mechanics, may result in better oxygenation, rapid lowering of plateau pressure in the first week, and possibly improved outcome.
Jack J. Haitsma, MD, PhD

jack.haitsma@utoronto.ca

Interdepartmental Division of Critical Care Medicine

St Michael's Hospital

Toronto, Ontario, Canada

Paolo Pelosi, MD

Department of Ambient Health and Safety

University of Insubria

Varese, Italy

Financial Disclosures: None reported.

1. Terragni PP, Rosboch G, Tealdi A, et al. Tidal hyperinflation during low tidal volume ventilation in acute respiratory distress syndrome. Am I Respir Crit Care Med. 2007;175(2):160-166.

2. Mercat A, Richard JC, Vielle B, et al; Expiratory Pressure (Express) Study Group. Positive end-expiratory pressure setting in adults with acute lung injury and acute respiratory distress syndrome: a randomized controlled trial. JAMA. 2008;299 (6):646-655

3. Amato MB, Barbas CS, Medeiros DM, et al. Effect of a protective-ventilation strategy on mortality in the acute respiratory distress syndrome. $N$ Engl J Med. 1998;338(6):347-354.

4. Villar J, Kacmarek RM, Perez-Mendez L, Aguirre-Jaime A. A high positive endexpiratory pressure, low tidal volume ventilatory strategy improves outcome in persistent acute respiratory distress syndrome: a randomized, controlled trial. Crit Care Med. 2006;34(5):1311-1318.

5. Quintel $M$, Pelosi $P$, Caironi $P$, et al. An increase of abdominal pressure increases pulmonary edema in oleic acid-induced lung injury. Am J Respir Crit Care Med. 2004;169(4):534-541.

To the Editor: I believe that the design of the Lung Open Ventilator Study by Dr Meade and colleagues ${ }^{1}$ made an error by adjusting PEEP according to $\mathrm{FIO}_{2}$, leading to overdistention of alveoli as evidenced by lower static compliance (tidal volume/[plateau pressure-end-expiratory pressure]) in the high PEEP group than in the lower PEEP group. ${ }^{2}$ The mean levels of compliance in the high and low PEEP groups were 0.41 and $0.42 \mathrm{~mL} / \mathrm{kg} / \mathrm{cm} \mathrm{H}_{2} \mathrm{O}$ on day 3 and 0.37 and $0.41 \mathrm{~mL} / \mathrm{kg} / \mathrm{cm} \mathrm{H}_{2} \mathrm{O}$ on day 7 , respectively. Despite a similar protocol, the same phenomenon was not observed in the ALVEOLI study, ${ }^{3}$ possibly due to the difference in patient population. The protocol change in the middle of the study allowing higher PEEP levels in the Lung Open Ventilator Study might have negatively affected the study results.

GUIDELINES FOR LETTERS. Letters discussing a recent JAMA article will have the best chance of acceptance if they are received within 4 weeks of the article's publication date. Letters may have no more than 3 authors. They should not exceed 400 words of text and 5 references. Letters reporting original research should not exceed 600 words and 6 references. They may have no more than 5 authors. All letters should include a word count. Letters must not duplicate other material published or submitted for publication. Letters will be published at the discretion of the editors and are subject to editing and abridgment. A signed statement for authorship criteria and responsibility, financial disclosure, copyright transfer, and acknowledgment is required for publication. Letters not meeting these specifications are generally not considered. Before submitting a Research Letter, please review the Instructions for Authors (July 2, 2008, or http://www.jama.com). Letters should be submitted via the JAMA online submission and review system at http://manuscripts.jama.com (note: do not include "www" before the URL). For technical assistance, please contact jama-letters@jama-archives.org.

Letters Section Editor: Robert M. Golub, MD, Senior Editor. 
The results of the Express study by Dr Mercat and colleagues ${ }^{4}$ could also have been different if the PEEP level had been adjusted according to compliance instead of plateau pressure, given the non-statistically significant increased mortality and duration of mechanical ventilation with higher levels of PEEP in the group with ALI but without ARDS. Aiming for the same level of plateau pressure in patients with mild lung injury might have led to more adverse effects by overextending the alveoli.

Although in their editorial Drs Gattinoni and Caironi ${ }^{5}$ suggested the direct assessment of lung recruitability by a dynamic lung imaging technique, getting a computed tomographic scan in all patients with ALI and ARDS seems impractical and may not be efficient because recruitability can change very quickly. ${ }^{2}$ Achieving maximal lung recruitment without overextending the alveoli could easily be done at the bedside by titrating PEEP to the greatest compliance while not exceeding a certain level of plateau pressure. For example, PEEP can be increased gradually on pressure control ventilation until a tidal volume declines or a plateau pressure exceeds 28 to $30 \mathrm{~cm} \mathrm{H}_{2} \mathrm{O}$, whichever comes first.

Yuji Oba, MD

obay@health.missouri.edu

Pulmonary, Critical Care, and Environmental Medicine

University of Missouri-Columbia

Financial Disclosures: None reported.

1. Meade MO, Cook DJ, Guyatt GH, et al; Lung Open Ventilation Study Investigators. Ventilation strategy using low tidal volumes, recruitment maneuvers, and high positive end-expiratory pressure for acute lung injury and acute respiratory distress syndrome: a randomized controlled trial. JAMA. 2008;299 (6):637-645.

2. Ferguson ND, Frutos-Vivar F, Esteban A, et al. Airway pressures, tidal volumes, and mortality in patients with acute respiratory distress syndrome. Crit Care Med. 2005;33(1):21-30.

3. Brower RG, Lanken PN, Maclntyre N, et al. Higher versus lower positive endexpiratory pressures in patients with the acute respiratory distress syndrome. N Engl J Med. 2004;351(4):327-336.

4. Mercat A, Richard JC, Vielle B, et al; Expiratory Pressure (Express) Study Group. Positive end-expiratory pressure setting in adults with acute lung injury and acute respiratory distress syndrome: a randomized controlled trial. JAMA. 2008;299 (6):646-655.

5. Gattinoni L, Caironi P. Refining ventilatory treatment for acute lung injury and acute respiratory distress syndrome. JAMA. 2008;299(6):691-693.

To the Editor: The study of PEEP settings in adults with ALI and ARDS by Dr Mercat and colleagues ${ }^{1}$ did not find a mortality benefit in patients in the increased recruitment (high-PEEP) group compared with patients in the minimal distension arm. Lungs of patients with ARDS are likely to be less compliant, with resulting higher plateau pressures during volume-controlled ventilation..$^{2,3}$ In the increased recruitment group, patients with ARDS, compared with patients with less ALI and more compliant lungs, would receive lower levels of PEEP at the target plateau pressure of $30 \mathrm{~cm} \mathrm{H}_{2} \mathrm{O}$. This PEEP level may have been close to that applied in the minimal distension group in which the PEEP level was restricted between 5 and $9 \mathrm{~cm} \mathrm{H}_{2} \mathrm{O}$. It is therefore possible that in patients with severe forms of lung injury, there may not have been meaningful differences between the actual PEEP levels achieved in the 2 groups. A protocol that required the PEEP level to be decreased with increasing severity of lung injury may have diluted the potential benefit of "high" PEEP in the increased recruitment group.

Analysis comparing the mean PEEP levels in the subgroups of patients with ARDS vs ALI without ARDS may provide some insight into whether this contributed to the negative study results.

Jigeeshu Divatia, MD

jdivatia@vsnl.com

Priya Ranganathan, MD

Department of Anaesthesiology, Critical Care and Pain

Tata Memorial Hospital

Mumbai, India

Financial Disclosures: None reported.

1. Mercat A, Richard JC, Vielle B, et al; Expiratory Pressure (Express) Study Group Positive end-expiratory pressure setting in adults with acute lung injury and acute respiratory distress syndrome: a randomized controlled trial. JAMA. 2008;299 (6):646-655

2. Murray JF, Matthay MA, Luce JM, Flick MR. An expanded definition of the adult respiratory syndrome. Am Rev Respir Dis. 1988;138(3):720-723.

3. Maclntyre NR. Respiratory system mechanics. In: Maclntyre NR, Branson RD, eds. Mechanical Ventilation. Philadelphia, PA: WB Saunders Co; 2001:146-160.

To the Editor: Dr Mercat and colleagues ${ }^{1}$ reported the results of the Express trial comparing a minimal alveolar distention strategy with a strategy aiming for maximal alveolar recruitment while limiting hyperinflation. Although there was no difference in the primary end point (28-day mortality rate), the maximal alveolar recruitment strategy resulted in more ventilator-free days, more organ failurefree days, and less frequent use of rescue therapy. However, there are certain points that merit attention.

First, the screening for PEEP weaning was determined by the $\mathrm{PaO}_{2}: \mathrm{FIO}_{2}$ ratio. This ratio depends on the PEEP level, which was by design not equal between groups. Higher PEEP level will result in higher $\mathrm{PaO}_{2}$ : $\mathrm{FIO}_{2}$ ratio, favoring early weaning in the increased recruitment group and possibly contributing to the reduced time spent on mechanical ventilation in this group.

Second, the amount of alveolar recruitment and alveolar hyperinflation by PEEP is a trade-off. ${ }^{2}$ The patients in the minimal alveolar distention group may have actually been treated with an unusually low PEEP level, lower than in the 2 trials that showed a beneficial effect with low tidal volume ventilation. ${ }^{3,4}$ In the ARDS Network trial, ${ }^{3}$ even the set PEEP (excluding intrinsic PEEP) was higher (9.4, 9.2, and $8.1 \mathrm{~cm} \mathrm{H}_{2} \mathrm{O}$ on days 1,3 , and 7 , respectively) than the total PEEP (including intrinsic PEEP) in this trial (8.4, 8.1, and $8.0 \mathrm{~cm} \mathrm{H}_{2} \mathrm{O}$ on days 1,3 , and 7 , respectively).

Although the strategy in the maximal alveolar recruitment strategy is appealing, hyperinflation may still occur in certain patients despite plateau pressure being below 30 $\mathrm{cm} \mathrm{H}_{2} \mathrm{O}^{2}$ This may result in a local and systemic inflammatory response syndrome, which could result in a worse outcome. ${ }^{2,3}$ Another strategy for individual titration of PEEP could be the simultaneous measurement of dead space. ${ }^{5} \mathrm{~A}$ combination of maximal compliance with the lowest dead 
space fraction could be another practical way to optimize the balance between derecruitment and hyperinflation.

\author{
L. M. A. Heunks, MD, PhD \\ l.heunks@ic.umcn.nl \\ J. G. van der Hoeven, MD, PhD \\ Radboud University Nijmegen Medical Centre \\ Nijmegen, the Netherlands
}

Financial Disclosures: None reported.

1. Mercat A, Richard JC, Vielle B, et al; Expiratory Pressure (Express) Study Group. Positive end-expiratory pressure setting in adults with acute lung injury and acute respiratory distress syndrome: a randomized controlled trial. JAMA. 2008;299 (6):646-655.

2. Terragni PP, Rosboch G, Tealdi A, et al. Tidal hyperinflation during low tidal volume ventilation in acute respiratory distress syndrome. Am J Respir Crit Care Med. 2007;175(2):160-166.

3. The Acute Respiratory Distress Syndrome Network. Ventilation with lower tidal volumes as compared with traditional tidal volumes for acute lung injury and the acute respiratory distress syndrome. N Engl J Med. 2000;342(18):1301-1308.

4. Amato MB, Barbas CS, Medeiros DM, et al. Effect of a protective-ventilation strategy on mortality in the acute respiratory distress syndrome. $N$ Engl J Med. 1998:338(6):347-354.

5. Maisch S, Reissmann H, Fuellekrug B, et al. Compliance and dead space fraction indicate an optimal level of positive end-expiratory pressure after recruitment in anesthetized patients. Anesth Analg. 2008;106(1):175-181.

To the Editor: The studies by Dr Meade and colleagues ${ }^{1}$ and Dr Mercat and colleagues ${ }^{2}$ were intended to test a strategy aimed at maximizing alveolar recruitment while limiting hyperinflation. To guarantee applicability at the bedside, both studies made use of fixed targets such as plateau pressures or PEEP/FIO 2 ratios with PEEP levels adjusted accordingly. Because PEEP levels were not primarily titrated, the question is how much this approach compromised the test of an "optimum-PEEP" in favor of a "feasible-PEEP."

In the Lung Open Ventilation Study, ${ }^{1}$ patients demonstrating easy lung recruitment, possibly those in whom the $\mathrm{FIO}_{2}$ could be immediately reduced to $40 \%$ (after recruiting maneuvers and an initial PEEP of $20 \mathrm{~cm} \mathrm{H}_{2} \mathrm{O}$ ), may have been immediately submitted to a PEEP of only $10 \mathrm{~cm} \mathrm{H}_{2} \mathrm{O}$. In contrast, patients not easily achieving recruitment, requiring $\mathrm{FIO}_{2}$ levels at or above $50 \%$ after the recruitment maneuver, were submitted to PEEP levels at or above $18 \mathrm{~cm} \mathrm{H}_{2} \mathrm{O}$ for many days. Whereas a PEEP of $10 \mathrm{~cm} \mathrm{H}_{2} \mathrm{O}$ was likely too low to stabilize the recently open tissue in the first case, a PEEP of $18 \mathrm{~cm} \mathrm{H}_{2} \mathrm{O}$ might be too high for the already open lung tissue in the second case. The insistence on a high PEEP level is not an efficient strategy for recruiting those collapsed units, ${ }^{3}$ especially after observing failure with an inspiratory pressure of $40 \mathrm{~cm} \mathrm{H}_{2} \mathrm{O}$. This binary treatment may have wasted an opportunity for those who could benefit the most from the recruitment maneuver while adding risk for those who could not get a clear benefit.

In the Express study, ${ }^{2}$ the healthiest patients, probably those with the lowest impairment in lung compliance, were by protocol design exposed to highest levels of PEEP (because the fixed $6 \mathrm{~mL} / \mathrm{kg}$ tidal volume would have produced low driving pressures, requiring the clinician to further increase PEEP levels until achieving plateau pressures of $28 \mathrm{~cm} \mathrm{H}_{2} \mathrm{O}$ ). In contrast, the sickest patients presenting with lowest compliance likely received a much lower PEEP.
João Batista Borges, MD jbborges@unisys.com.br Carlos Roberto Ribeiro Carvalho, MD

Marcelo Britto Passos Amato, MD

University of São Paulo

São Paulo, Brazil

Financial Disclosures: None reported

1. Meade MO, Cook DJ, Guyatt GH, et al; Lung Open Ventilation Study Investigators. Ventilation strategy using low tidal volumes, recruitment maneuvers, and high positive end-expiratory pressure for acute lung injury and acute respiratory distress syndrome: a randomized controlled trial. JAMA. 2008;299 (6):637-645.

2. Mercat A, Richard JC, Vielle B, et al; Expiratory Pressure (Express) Study Group. Positive end-expiratory pressure setting in adults with acute lung injury and acute respiratory distress syndrome: a randomized controlled trial. JAMA. 2008;299 (6):646-655.

3. Borges JB, Okamoto VN, Matos GF, et al. Reversibility of lung collapse and hypoxemia in early acute respiratory distress syndrome. Am J Respir Crit Care Med. 2006;174(3):268-278.

In Reply: Drs Haitsma and Pelosi state that oxygenation may be improved by a recruitment maneuver that leads to a shortterm increase in plateau pressure. Oxygenation, which we do not consider a solid end point in patients with ALI/ ARDS, ${ }^{1}$ was already markedly improved in the high PEEP group of the Express trial. Recruitment maneuvers can have severe adverse effects, and in the absence of evidence that fully recruiting the lung is clinically important, we preferred not to recommend such maneuvers in our trial.

Dr Oba suggests that a PEEP titration based on the static compliance of the respiratory system could result in a better outcome than the method we used. Our experience is that compliance is difficult to use at the bedside for PEEP titration. The changes in compliance induced by increased PEEP are often quite small, and recruitment can be associated with a decrease in linear compliance measured at a given airway pressure..$^{2,3}$ In addition, the sigmoidal shape of the pressure-volume curve makes it difficult to interpret such measurement. We therefore remain unsure whether compliance could improve PEEP titration.

Drs Divatia and Ranganathan are correct that the method we used to titrate PEEP in the increased recruitment group could have resulted in moderate levels of PEEP in patients with very low compliance. However, only 23 patients $(6 \%)$ in this group had a PEEP level on day 1 lower than $10 \mathrm{~cm} \mathrm{H}_{2} \mathrm{O}$. The use of higher levels of PEEP in these patients would have resulted in high levels of plateau pressure and an increased risk of overdistention. Patients with ALI with or without ARDS had similar mean levels of PEEP on day 1.

Drs Heunks and van der Hoeven suggest that the better oxygenation in the increased recruitment group could have accelerated the weaning process. The mean (SD) PEEP level in the minimal distension arm $\left(6.7[1.8] \mathrm{cm} \mathrm{H}_{2} \mathrm{O}\right.$ at day 3) was very close to the $5 \mathrm{~cm} \mathrm{H}_{2} \mathrm{O}$ level chosen for PEEP weaning trials. The oxygenation threshold for testing PEEP weaning was by design relatively low $\left(\mathrm{PaO}_{2}: \mathrm{FIO}_{2}>150\right)$ to avoid favoring one group vs the other. The PEEP-weaning process might have been achieved at a similar rate in both groups

(Reprinted) JAMA, July 2, 2008—Vol 300, No. $1 \quad 41$ 
if high PEEP had altered nothing but oxygenation in the high PEEP group. However, the earlier PEEP-weaning test success in the increased recruitment group suggests a specific effect of high PEEP, perhaps allowing a better reopening or recruitment of the lung and a better tolerance of a decreased PEEP level.

In the low PEEP group, the goal was to minimize alveolar distension by all means. The mean PEEP level in this arm was very close to the PEEP levels reported in a recent international survey. ${ }^{4}$ Three studies have shown no mortality difference using 4 to $5 \mathrm{~cm} \mathrm{H}_{2} \mathrm{O}$ differences in PEEP levels, ${ }^{5}$ and it is unlikely that less than $1 \mathrm{~cm} \mathrm{H} \mathrm{H}_{2} \mathrm{O}$ of PEEP makes a substantial difference in outcome. Dead space measurement may help individual titration. However, dead space is greatly influenced by its alveolar component in ARDS. Alveolar dead space may increase because of hyperinflation caused by increasing pressures but may also decrease because of shunt reduction. Therefore, a decrease or no change in dead space may mask a real hyperinflation. It therefore remains to be tested whether assessing dead space is sensitive enough in severely hypoxemic patients with high shunt.

In response to Dr Borges and colleagues, our post hoc analyses based on the quartiles of oxygenation or ALI vs ARDS suggest that our increased recruitment approach may not work in the less severe patients (eg, ALI without ARDS), resulting in excessive PEEP levels in these patients. The use of higher levels of PEEP in patients with very low compliance would have resulted in excessively high levels of plateau pressure and potentially an increased risk of overdistention. The beneficial effect on outcome of such a strategy remains to be demonstrated. We are not aware of simple validated bedside tools to better individualize the ventilator therapy.

Alain Mercat, MD

almercat@chu-angers.fr

Département de Réanimation Médicale et Médecine Hyperbare CHU d'Angers

Angers, France

Jean-Christophe Richard, MD

Service de Réanimation Médicale

CHU de Rouen

Rouen, France

Laurent Brochard, MD

Service de Réanimation Médicale

AP-HP, Centre Hospitalier Albert Chenevier-Henri Mondor

Créteil, France

Financial Disclosures: None reported

1. The Acute Respiratory Distress Syndrome Network. Ventilation with lower tida volumes as compared with traditional tidal volumes for acute lung injury and the acute respiratory distress syndrome. N Engl J Med. 2000;342(18):1301-1308.

2. Katz JA, Ozanne GM, Zinn SE, Fairley HB. Time course and mechanisms of lung volume increase with PEEP in acute pulmonary failure. Anesthesiology. 1981; 54(1):9-16

3. Jonson B, Richard JC, Straus C, Mancebo J, Lemaire F, Brochard L. Pressurevolume curves and compliance in acute lung injury: evidence of recruitment above the lower inflection point. Am J Respir Crit Care Med. 1999;159(4 pt 1):1172 1178.

42 JAMA, July 2, 2008-Vol 300, No. 1 (Reprinted)
4. Brun-Buisson C, Minelli C, Bertolini G, et al. Epidemiology and outcome of acute lung injury in European intensive care units: results from the ALIVE study. Intensive Care Med. 2004;30(1):51-61.

5. Gattinoni $L$, Caironi $P$. Refining ventilatory treatment for acute lung injury and acute respiratory distress syndrome. JAMA. 2008;299(6):691-693.

In Reply: In response to Dr Oba and Drs Borges and colleagues, we agree that the ability to identify those patients with ALI and ARDS who are most likely to benefit from an open-lung approach is a laudable goal. We hope that our experimental approach to PEEP titration, while taking into consideration lung protection, oxygenation, hemodynamics, and barotrauma, will be improved on in the future with more sophisticated methods of individualizing ventilatory management.

We agree with Borges et al that our approach may have led to an open lung in some patients and overdistention in others. To this extent, the modification in our protocol may have increased the potential for a negative study, as Oba suggests, although our analyses do not detect this effect. Our experimental approach was based on a consensus of individuals, considering current research evidence and routine clinical practices at that time. From our perspective, this choice was not mistaken. Many approaches to PEEP titration have been suggested, including pressure-volume curve analyses, assessment of the stress index, application of various imaging techniques, the specific methods referred to by Borges et al and several others. To date, however, there is no consensus on the optimal strategy for individualized PEEP titration. We look forward to further research addressing these fundamental issues for patients with ALI and ARDS.

Maureen O. Meade, MD, MSc

meadema@hhsc.ca

McMaster University

Hamilton, Ontario, Canada

Thomas E. Stewart, MD

University of Toronto

Toronto, Ontario

Financial Disclosures: None reported.

In Reply: Dr Oba proposes an approach to setting PEEP during ALI/ARDS based on the following conceptual model: by applying higher levels of PEEP the lung will be recruited and, with the tidal volume distributed across a greater portion of lung parenchyma, the plateau pressure will decrease; ie, the compliance of the respiratory system will increase. After the recruitment, a further increase of PEEP would lead to alveolar overdistention, and the compliance of the respiratory system would decrease accordingly. Indeed, the "best PEEP" would coincide with the "best compliance."

Investigators have been approaching this issue for more than 35 years $^{1,2}$ without having reached a solution. In 1975, Suter et $\mathrm{al}^{3}$ formulated the same proposal (best $\mathrm{PEEP}=$ maximum oxygen transport $=$ maximum compliance). Unfortunately, things are not so simple for a number of reasons. First, lung recruitment is a continuous in- 
spiratory phenomenon occurring up to total lung capacity ${ }^{4}$; it is impossible to dissociate lung recruitment from lung overdistension. Second, this mixture of phenomena is present at different degrees according to the maximal lung recruitability, and the recruitability of the lung in ALI/ARDS may vary from $0 \%$ to $30 \%$ or $40 \%$ of the lung parenchyma. ${ }^{5}$ Third, the mechanical characteristics of the chest wall greatly affect the transpulmonary pressure, the real "distending force" of the lung. ${ }^{6}$ The compliance of the respiratory system depends on both the chest wall and the lung. It follows that the same plateau pressure may mask completely different transpulmonary pressures.

Each patient is unique. We realize that computed tomographic scanning may sound impractical, but we do not know of better current approaches to characterize the pulmonary pathophysiology of each patient.

Luciano Gattinoni, MD, FRCP

gattinon@policlinico.mi.it

Pietro Caironi, MD

Dipartimento di Anestesia, Rianimazione (Intensiva e

Subintensiva) e Terapia del Dolore

Fondazione IRCCS-Ospedale Maggiore Policlinico Mangiagalli Regina Elena di Milano

Milan, Italy

Financial Disclosures: None reported.

1. Falke KJ, Pontoppidan $H$, Kumar A, Leith DE, Geffin B, Laver MB. Ventilation with end-expiratory pressure in acute lung disease. J Clin Invest. 1972;51(9): 2315-2323.

2. Villar J. Low vs high positive end-expiratory pressure in the ventilatory management of acute lung injury. Minerva Anestesiol. 2006;72(6):357-362.

3. Suter PM, Fairley B, Isenberg MD. Optimum end-expiratory airway pressure in patients with acute pulmonary failure. N Engl J Med. 1975;292(6):284-289.

4. Crotti $S$, Mascheroni D, Caironi $P$, et al. Recruitment and derecruitment during acute respiratory failure: a clinical study. Am J Respir Crit Care Med. 2001; 164(1):131-140.

5. Gattinoni $L$, Caironi $P$, Cressoni $M$, et al. Lung recruitment in patients with the acute respiratory distress syndrome. N Engl J Med. 2006;354(17):1775-1786. 6. Gattinoni L, Pelosi P, Suter PM, Pedoto A, Vercesi P, Lissoni A. Acute respiratory distress syndrome caused by pulmonary and extrapulmonary disease: different syndromes? Am J Respir Crit Care Med. 1998;158(1):3-11.

\section{Randomized Controlled Trials in Critical Care Medicine}

To the Editor: Randomized controlled trials (RCTs) are often considered the highest form of clinical evidence. However, RCTs providing evidence for reduced mortality using a treatment for patients in intensive care units (ICUs) are scarce. The few trials demonstrating survival advantage were incorporated in the Surviving Sepsis Campaign. ${ }^{1}$ However, even some of these trials have been challenged. ${ }^{2}$ We are aware of no large RCTs in the ICU setting with beneficial results that have been confirmed by a second RCT. Given that there are also studies with survival disadvantage in the treatment arm, ${ }^{2}$ it is possible that the outcome of these studies reflects chance: $2.5 \%$ negative, $2.5 \%$ positive, and $95 \%$ no association.

Two very sophisticated trials were designed to test a survival advantage of an open lung strategy for patients receiv- ing mechanical ventilation., ${ }^{3,4}$ Although based on sound physiological reasoning and preclinical data, both studies failed to find a benefit. An accompanying editorial by Drs Chiche and Angus ${ }^{5}$ highlighted the problems of conducting an RCT in critically ill patients. I would like to raise 1 issue that they did not discuss.

Many ICU studies are powered to show a relative reduction in mortality of $20 \%$ or absolute reduction of $10 \% .{ }^{3,4} \mathrm{How}-$ ever, mortality in ICU patients is multifactorial, and treating only 1 factor is unlikely to result in such a substantial improvement. Conversely, trying to prove smaller benefits will require either more homogeneous patient populations and treatments or numbers of participants comparable with outcome studies in cardiac disease, hypertension, and diabetes. Neither option seems feasible. Perhaps redirecting some of the enormous effort put into RCTs toward redesigning standards for evidence-based intensive care medicine would allow movement forward. In the meantime, the expert clinician mentioned by Chiche and Angus remains indispensable.

J. G. Zijlstra, MD, PhD

j.g.zijlstra@int.umcg.nl

J. J. M. Ligtenberg, MD, PhD

University Medical Center Groningen

Groningen, the Netherlands

A. R. J. Girbes, MD, PhD

Free University Medical Center

Amsterdam, the Netherlands

Financial Disclosures: None reported

1. Dellinger RP, Levy MM, Carlet JM, et al. Surviving Sepsis Campaign: international guidelines for management of severe sepsis and septic shock: 2008. Crit Care Med. 2008;36(1):296-327.

2. Marik PE, Varon J. Intensive insulin therapy in the ICU: is it now time to jump off the bandwagon? Resuscitation. 2007:74(1):191-193.

3. Mercat A, Richard JC, Vielle B, et al; Expiratory Pressure (Express) Study Group. Positive end-expiratory pressure setting in adults with acute lung injury and acute respiratory distress syndrome: a randomized controlled trial. JAMA. 2008;299 (6):646-655.

4. Meade MO, Cook DJ, Guyatt GH, et al; Lung Open Ventilation Study Investigators. Ventilation strategy using low tidal volumes, recruitment maneuvers, and high positive end-expiratory pressure for acute lung injury and acute respiratory distress syndrome: a randomized controlled trial. JAMA. 2008;299 (6):637-645.

5. Chiche JD, Angus DC. Testing protocols in the intensive care unit: complex trials of complex interventions for complex patients. JAMA. 2008;299(6):693-695.

In Reply: We appreciate the high esteem in which Dr Zijlstra and colleagues place RCTs and join them in wishing that more trials would be undisputedly positive. They suggest changing, and possibly lowering, the standards of evidence on which intensivists should base care because the interventions tested in RCTs generally target only 1 of many problems; thus, outcomes such as mortality are hard to modify and, by extension, the trials will always have a high likelihood of failure.

Although we do not believe that RCTs should be abandoned, we do agree that RCTs should continue to test interventions better designed to influence important clinical outcomes. The 2 particular trials we discussed, ${ }^{1,2}$ although attempting to manipulate a rather narrow spectrum of the wide set of physiologic derangements seen in critically ill 